\title{
The Cost-Effectiveness of Pulsed-Dye Laser Therapy Among Thai Patients with Facial Port-Wine Stain: A Retrospective Study and Economic Evaluation
}

\author{
Rungsima Wanitphakdeedecha (D) - Tatre Jantarakolica • \\ Janice Natasha C. Ng • Chadakan Yan • Yanisorn Nanchaipruek • \\ Nuttagarn Jantanapornchai · Woraphong Manuskiatti • \\ Tatchalerm Sudhipongpracha
}

Received: November 18, 2020 / Published online: January 22, 2021

(c) The Author(s) 2021

\section{ABSTRACT}

Introduction: Port-wine stain (PWS) is a progressive capillary malformation that does not resolve spontaneously without treatment. Pulsed dye laser (PDL) is currently the gold standard treatment for PWS, although it is difficult to attain complete clearance and recurrences are common. This study determined the cost-effectiveness of PDL treatment among Thai patients with facial PWS.

Methods: This was a retrospective chart review of 109 Thai patients with facial PWS and treated with PDL at Siriraj Hospital, Thailand from January 2008 to December 2017. The primary outcome of the study was the cost-effectiveness of PDL treatment in the clinical improvement of facial PWS.

R. Wanitphakdeedecha $(\varangle) \cdot$ J. N. C. Ng · C. Yan . Y. Nanchaipruek · N. Jantanapornchai ·

W. Manuskiatti

Department of Dermatology, Faculty of Medicine

Siriraj Hospital, Mahidol University, Bangkok,

Thailand

e-mail: rungsima.wan@mahidol.ac.th

R. Wanitphakdeedecha · T. Sudhipongpracha College of Interdisciplinary Studies, Thammasat

University, Bangkok, Thailand

T. Jantarakolica

Faculty of Economics, Thammasat University,

Bangkok, Thailand
Results: Ten PDL treatment sessions will have an expected clinical improvement of $60 \%$. At the 10th treatment, the marginal incremental improvement with respect to visit is approximately equal to one. The succeeding treatment sessions will only give an additional improvement of $5-10 \%$.

Conclusion: A total of 10 PDL treatment sessions was considered cost-effective as it can achieve 60\% clinical improvement among Thai patients with facial PWS.

Keywords: Cost-effectiveness; Port wine stain; Pulsed dye laser

\section{Key Summary Points}

Port-wine stain (PWS) is a progressive capillary malformation that does not resolve spontaneously without treatment.

Pulsed dye laser (PDL) is currently the gold standard treatment for PWS, although it is difficult to attain complete clearance and recurrences are common.

A total of 10 PDL treatment session is considered cost-effective as it can achieve $60 \%$ clinical improvement among Thai patients with facial PWS.

The succeeding treatment after the 10th session can only give an additional improvement of $5-10 \%$. 


\section{DIGITAL FEATURES}

This article is published with digital features, including a summary slide, to facilitate understanding of the article. To view digital features for this article go to https://doi.org/10.6084/ m9.figshare.13526564.

\section{INTRODUCTION}

Port-wine stain (PWS) is a congenital capillary malformation commonly found in the head and neck region, and observed in approximately $0.3 \%$ of the newborns [1]. It initially presents as a pink or red patch and eventually progresses to dark purple nodules with hypertrophy, which can be more resistant to treatment [2]. PWS can impart a psychological burden to the patients and was reported to be associated with high emotional stress and decreased quality of life in both children and adults [3].

Previous therapeutic methods for PWS include excision with skin grafting, cryotherapy, ionizing radiation, dermabrasion, electrotherapy, or tattooing; however, these are no longer used because of poor results and scarring [4]. Argon laser was the first laser developed to treat PWS, but it was associated with permanent hypopigmentation, textural changes, and scarring [2].

The gold standard treatment for PWS is the pulsed dye laser (PDL), which selectively targets hemoglobin, resulting in the destruction of the capillary malformation while sparing the surrounding tissues [5]. An appropriate cooling system is essential to minimize the complications of skin damage caused by epidermal heating and to reduce the pain during treatment [6]. The response rate of PWS to PDL is associated with different factors such as age at treatment, location, size of lesion, presence of existing hyperplastic lesion, and the number of treatments [5]. Improvement was observed in patients with PWS who underwent an average of 4-5 laser sessions $[5,7]$. The efficacy of PDL varied between different areas and facial PWS showed better response compared to the lesions found in the neck, trunk, or limbs [8]. Common complications include edema and purpura, although some patients were reported to have blistering, crusting, and hyperpigmentation [6].

PDL is an effective treatment for PWS; however, multiple treatments are necessary to attain good clearance, and the possibility of recurrences are common. Laser treatment should be started as soon as possible especially when hypertrophy is detected, to avoid complications and poor response to treatment [9]. The acquisition of treatment may be limited due to the high cost of laser treatment. The objective of this study was to determine the cost-effectiveness of PDL treatment among Thai patients with facial PWS.

\section{METHODS}

In this retrospective study, we gathered information on 118 patients with PWS who underwent laser treatment at Siriraj Hospital, Thailand from January 2008 to December 2017. Patients with age ranging from 0 to 70 years old, diagnosed with facial PWS and treated with 595 nm PDL V Beam ${ }^{\circledR}$ (Candela Corp, Wayland, MA, USA), 585 nm PDL Cynergy ${ }^{\mathrm{TM}}$ (Cynosure, Westford, MA, USA), or a combination of $585 \mathrm{~nm}$ PDL with long pulsed QS $1064 \mathrm{~nm}$ Cynergy $^{\mathrm{TM}}$ Multiplex (Cynosure, Westford, MA, USA) were included in the study. Exclusion criteria included subjects who received fewer than two laser treatments and those who failed to attend follow-up. A total of 109 patients were eligible to be included in this study. Detailed information such as age, sex, laser parameters (spot size, fluence, pulse duration), number of treatments, treatment outcome, and cost of laser per session were also recorded.

The primary outcome of the study was the cost-effectiveness of PDL treatment in the clinical improvement of facial PWS. Descriptive analysis was used for the demographic data. The data were analyzed as bivariate analysis using parametric, nonparametric, and linear panel data models. Treatment efficacy was analyzed using propensity score matching (PSM). The statistical analysis was performed using Stata (StataCorp. 2015. Stata Statistical Software: Release 14. College Station, TX: StataCorp LP) 
and a $p$ value less than 0.05 was considered statistically significant.

In order to determine the improvement of PWS lesions, the change in the percentage of clinical improvement was analyzed using the linear visit-based panel data model, which was computed as:

$$
\begin{aligned}
\Delta Y_{i t}= & \beta_{0}+\beta_{1} t+\beta_{2} t^{2}+\beta_{3} Y_{i t-1}+\beta_{4} L_{i t}+\beta_{5} \mathrm{FL}_{i t} \\
& +\beta_{6} \mathrm{~L}_{1064}+\beta_{8} \mathrm{AGE}_{i t}+\alpha_{i}+\varepsilon_{i t}
\end{aligned}
$$

where $\Delta Y_{i t}=$ change in the percentage of clinical improvement of patient $i$ at treatment session $t . Y_{i t-1}=$ percentage of clinical improvement of patient $i$ at previous treatment session $t-1 ; t=$ number of laser treatment session. $L_{i t}=$ Dummy variable for laser type used to treat patient $i$ at treatment session $t$. Its value equals zero for PDL and one for Cynergy ${ }^{\mathrm{TM}}$. $\mathrm{FL}_{i t}=$ Fluence of $\mathrm{PDL}$ used to treat patient $i$ at treatment session $t$. L1064 = Dummy variable for the use of Nd YAG Cynergy $^{\mathrm{TM}}$ laser to treat patient $i$ at treatment session $t$. Its value equals zero for $595 \mathrm{~nm}$ PDL V Beam ${ }^{\circledR}$ (Candela Corp, Wayland, MA, USA) and one for a combination of $585 \mathrm{~nm}$ PDL with long pulsed QS $1064 \mathrm{~nm}$. AGE $i t=$ Age of patient $i$ at treatment session $t . \alpha_{i}=$ Cross-sectional random effects of patient $i . \varepsilon_{i t}=$ Stochastic random error of patient $i$ at treatment session $t$.

The model was estimated using pooled least squares, fixed-effects (FE) and random-effects estimation methods. The optimal number of laser treatments was defined as the point where the number of treatments leads the marginal additional percentage improvement to be equal to one. In other words, the partial derivative of the change in improvement with respect to the number of laser treatment sessions $(t)$ is equal to one $^{1}$ or $\frac{\partial \Delta Y_{i t}}{\partial t}=1$.

\footnotetext{
1 The change in the percentage of clinical improvement follows a quadratic function and during the first few treatment sessions, the marginal change is assumed to be increasing at a diminishing rate. During the first treatment sessions, the marginal change is expected to be greater than one, which means that it is cost-effective to perform the treatment. The subsequent treatment sessions with a marginal improvement of less than one would be considered as economically inefficient.
}

In order to reconfirm the optimal number of treatment sessions, independent sample $t$ test and PSM treatment effects test were also performed. These were done to compare the average improvement per treatment session between the two groups (either within or more than the optimal number of treatment sessions).

This study was approved by the ethics committee of the Siriraj Institutional Review Board. Written informed consent was obtained from all subjects prior to their enrollment in the study and the patient's and parents' consent for publication was obtained. This was performed in accordance with the Helsinki Declaration of 1964 and its later amendments and has been registered in the Thai Clinical Trials Registry (TCTR) under the identification number TCTR20200909002.

\section{RESULTS}

Out of 118 subjects, 109 (92.4\%) were included in the final analysis. Nine subjects were not included because of incomplete chart data. The demographic data of the subjects enrolled are presented in Table 1.

The proposed regression model estimated using pooled least squares, FE, and random-effects estimation methods ${ }^{2}$ are described in Table 2. According to FE and Hausman test, the most appropriate result is from the FE estimation method. The significant results of the treatment sessions $(t)$ and square of treatment sessions $\left(t^{2}\right)$ confirmed the hypothesis that the clinical improvement of PWS follows a quadratic function. In other words, the clinical improvement based on the number of treatment sessions increases at a diminishing rate. Previous improvement of the patient $\left(Y_{i t}\right)$ significantly and diminishingly affected the additional improvement of the current treatment session. $L$ is the variable for the laser type used

\footnotetext{
2 Both FE estimation and random-effects estimation methods can be used to solve endogeneity bias from individual characteristics of each subject. Conceptually and practically, the estimated results from both methods are preferable to that from the traditional least squares, including pooled least squares estimation method.
} 
Table 1 Demographic data of subjects enrolled in the study

\begin{tabular}{ll}
\hline Characteristics & $\begin{array}{l}\text { Total, } \boldsymbol{n}(\%) \\
(\boldsymbol{N}=\mathbf{1 0 9})\end{array}$ \\
\hline Sex, $n(\%)$ & $46(42.2)$ \\
Male & $63(57.8)$ \\
Female & $4(0.03-70)$ \\
Age (years), median (min-max) & \\
595 nm PDL V Beam ${ }^{\circledR}$ & $4.0-10.0$ \\
Spot size (mm) & $0.45-12.0$ \\
Fluence (J/cm $\left.{ }^{2}\right)$ & $0.4-12.0$ \\
Pulse duration (ms) & \\
585 nm PDL Cynergy ${ }^{\mathrm{TM}}$ & $7.0-10.0$ \\
Spot size (mm) & $2.0-8.0$ \\
Fluence (J/cm $\left.{ }^{2}\right)$ & $0.5-15.0$ \\
Pulse duration (ms) & \\
$585-1064 \mathrm{~nm}$ PDL Cynergy ${ }^{\mathrm{TM}}$ Multiplex & \\
Spot size (mm) & $7.0-10.0$ \\
Fluence (J/cm $\left.{ }^{2}\right)$ & $6.0-40.0$ \\
Pulse duration (ms) & $15.0-35.0$ \\
Cost of laser per session (baht), min-max & $200-7500$ \\
\hline
\end{tabular}

and it showed that $585 \mathrm{~nm}$ PDL Cynergy ${ }^{\mathrm{TM}}$ had a significantly better improvement of $5.34 \%$ when compared with $595 \mathrm{~nm}$ PDL V Beam ${ }^{\circledR}$. The increase in the "FL" or fluence of the PDL by $1 \mathrm{~J} / \mathrm{cm}^{2}$ can significantly improve the clearance of the lesion by $1.34 \%$. And lastly, the variable "L1064" or long-pulsed Nd YAG $1064 \mathrm{~nm}$ laser showed that the treatment using combination wavelengths can significantly improve lesion clearance by $6.52 \%$.

The analysis to determine the optimal number of laser treatment is shown in Fig. 1, from which it was concluded that 10 PDL laser treatment sessions will have an expected clinical improvement of $60 \%$. At the 10 th treatment, the marginal incremental improvement with respect to visit is approximately equal to one. The first five treatments (treatments 1-5) are
Table 2 Estimated results of linear panel data regression model

\begin{tabular}{llll}
\hline Variable & Pooled & RE & FE \\
\hline$t$ & $-1.2016^{* * *}$ & 0.3268 & $2.2045^{* * *}$ \\
$t^{2}$ & $0.0356^{* * *}$ & -0.0031 & $-0.0596^{* * *}$ \\
$y_{t-1}$ & $-0.1354^{* * *}$ & $-0.2921^{* * *}$ & $-0.4537^{* * *}$ \\
$L$ & 0.0273 & 2.3429 & $5.3454^{* *}$ \\
FL & $0.9164^{* * *}$ & $1.2374^{* * *}$ & $1.3467^{* *}$ \\
L1064 & -0.7105 & 2.6671 & $6.5278^{* *}$ \\
Age & $-0.0761^{* *}$ & -0.0730 & 0.5066 \\
Constant & $15.1281^{* * *}$ & $11.6588^{* * *}$ & 1.0412 \\
Patient visit & 330 & 330 & 330 \\
Patients & & 86 & 86 \\
$F$ test & $24.457^{* * *}$ & & $19.383^{* * *}$ \\
Chi-square test & & $135.405^{* * *}$ & \\
$R^{2}$ & 0.3471 & 0.4873 & 0.5192 \\
RMSE & 8.0599 & 6.5655 & 5.3294 \\
FE test & & & $3.5891^{* * *}$ \\
Hausman & & & $73.2575^{* * *}$ \\
\hline
\end{tabular}

Significant at ${ }^{*} 0.1,{ }^{* *} 0.05,{ }^{* * *} 0.01$

expected to provide $40 \%$ improvement while the next five treatments (treatments 6-10) will lead to an additional improvement of $20 \%$. With the rapid drop in its effectiveness in clinical improvement, the third five treatments (visits 11-15) will only give an additional improvement of $10 \%$ while the fourth five treatments (treatments 16-20) will only provide less than 5\% improvement. Therefore, economically speaking the optimal number of treatment sessions is 10 (Fig. 2).

To confirm the optimal number of treatment sessions, independent sample $t$ test and PSM test between the two groups (within or more than ten visits) were performed. As shown in Table 3, both test results revealed significant differences between the two groups. The mean difference between the two groups was 9.53 per treatment session with a significant 


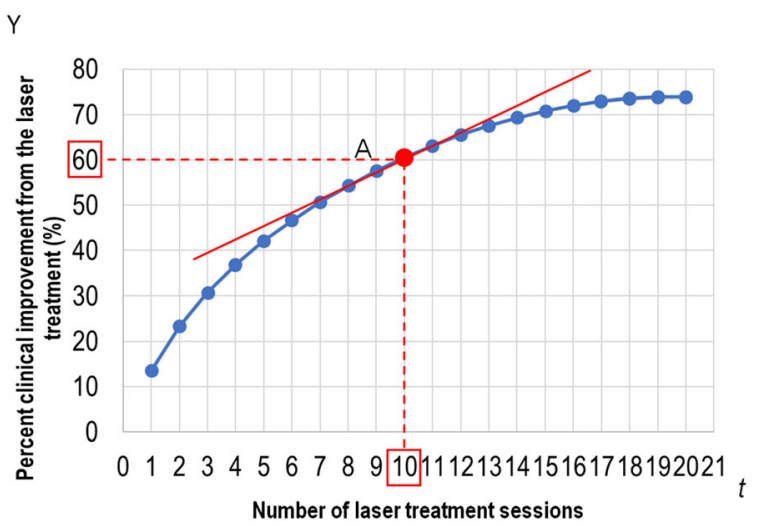

Fig. 1 Prediction of the clinical improvement from the laser treatment sessions based on the estimated model FE in Table 2. $Y=$ Percentage clinical improvement from the laser treatment (\%); $t=$ number of laser treatment sessions. From the estimated of model FE in Table 2, $\widehat{\Delta Y}_{i t}=1.041+2.205 t-0.0596 t^{2}-0.454 Y_{i t-1}+$ $5.345 L_{i t}+1.347 \mathrm{FL}_{i t}+6.528 \mathrm{~L} 1064_{i t}+0.408 \mathrm{AGE}_{i t}$. To obtain the optimal number treatment visits, $\frac{\partial \widehat{\Delta Y_{i t}}}{\partial t}=1$. Then, $\frac{\partial \widehat{\Delta Y_{i t}}}{\partial t}=2.205-0.119 t=1$. As a result, the optimal number of treatment visits $t=10.1 \approx 10$ times. The red line is the efficiency line whose the slope equals 1 . It is a tangent of the prediction of clinical improvement curve from the estimated model FE in Table 2 at point $\mathrm{A}$, which indicates that 10 laser treatment sessions provided the most economical improvement

independent $t$ test of 8.5211. Additionally, PSM treatment effect analysis was performed to avoid bias caused by the specific individual characteristics of each subject. The average treatment effect or the adjusted mean difference is 5.95 per treatment session and the significant $Z$ test value is 5.74 . Therefore, the recommended 10 treatment sessions were confirmed.

\section{DISCUSSION}

Facial PWS has a significant negative impact on the quality of life and psychological health [10]. A previous study reported that patients with PWS showed better psychosocial status after their treatment and early management presented with favorable results [11].

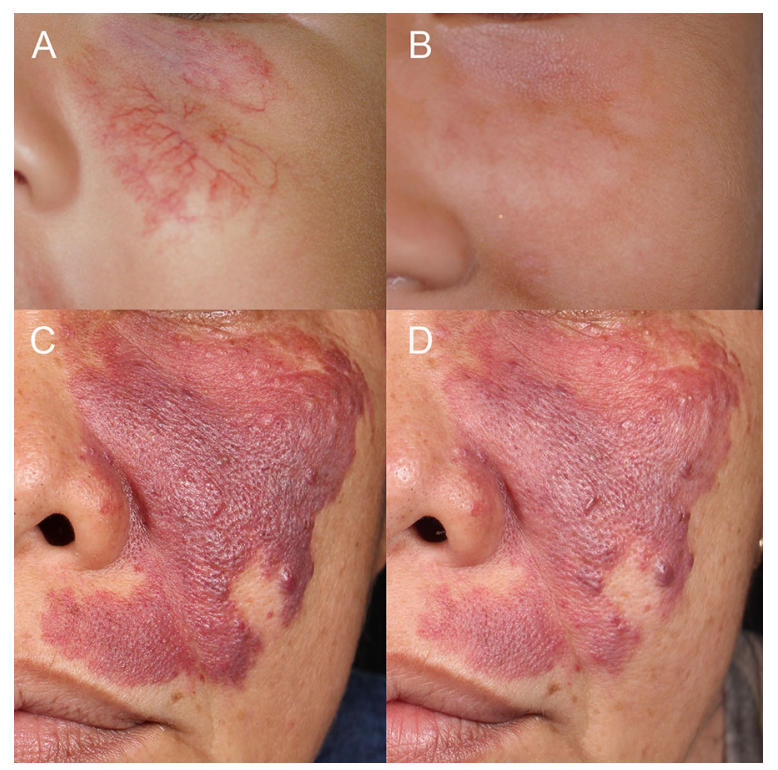

Fig. 2 Representative clinical photographs of facial PWS at baseline (a and $\mathbf{c}$ ) and after the laser treatment $(\mathbf{b}$ and $\mathbf{d})$

Several laser and light treatment modalities have been introduced, including PDL, neodymium-doped yttrium aluminum garnet (Nd:YAG) laser, alexandrite laser, intense pulsed light, copper vapor laser, photodynamic therapy, or a combination of these modalities $[12,13]$. At present, PDL is the treatment of choice owing to its clinical efficacy [14]. This laser utilizes the principle of selective photothermolysis to injure the ectatic dermal capillaries, thus reducing the redness and flattening of the lesion [15]. The most successful responses to PDL were seen in young patients (less than 1 year old) with small PWS (less than $20 \mathrm{~cm}^{2}$ ) located over the bony areas of the face, such as the central forehead [16]. PDL should be considered as an essential treatment modality as a result of the natural evolution of facial PWS that includes formation of vascular nodules, tissue hypertrophy, and a decrease in facial mobility that can develop later if untreated [4].

To evaluate the impact of PWS on the quality of life, it was reported that patients were willing to pay $11.8 \%$ of their monthly income and would offer a mean value of $1.2 \mathrm{~h}$ per day for an imaginary therapy leading to a complete cure of 
Table 3 Independent sample $t$ test and PSM treatment effect test of two groups

\begin{tabular}{lllll}
\hline & Patient visit & Mean & SD & Test \\
\hline Total & 534 & 11.25 & 12.90 & \\
Within 10 visits & 360 & 14.36 & 13.92 & \\
More than 10 visits & 174 & 4.83 & 7.01 & \\
Differences & & 9.53 & 1.12 & $8.5211^{* * *}$ \\
PSM $^{\text {a }}$ ATET $^{\mathrm{b}}$ & & 5.95 & 1.04 & $5.7400^{* * *}$ \\
\hline
\end{tabular}

Significant at ${ }^{*} 0.1,{ }^{* *} 0.05,{ }^{* * *} 0.01$

${ }^{a}$ The test of the differences is independent sample $t$ test

b The mean difference is the average treatment effect on the treated (ATET) computed using propensity score matching (PSM) and the test is $Z$ test of this ATET

their skin problem [17]. Possible delay in the treatment could involve the decision of parents in weighing the future social risk of PWS against the pain of laser therapy and its costs [18].

In our study, we also reported that the use of a combination wavelength $(585 \mathrm{~nm}$ PDL with long pulsed QS $1064 \mathrm{~nm}$ ) to treat PWS can significantly improve the clinical outcome by $6.52 \%$ when compared to using PDL wavelength alone. This finding was consistent with previous studies as well [19-21]. The PDL energy converts hemoglobin to methemoglobin, while the $1064 \mathrm{~nm}$ energy is absorbed more by methemoglobin leading to better clinical clearance [22]. Furthermore, the increase in PDL fluence can lead to better clinical outcome but the endpoint must be monitored to avoid possible complications.

In our study, the optimal number of PDL treatment is 10 sessions to achieve at least 60\% clinical improvement. The succeeding treatment after the 10th treatment can only give an additional improvement of 5-10\%. These findings were consistent with another study among patients with PWS and Fitzpatrick skin types (FSTs) IV and V, wherein 8-10 PDL sessions achieved $61-80 \%$ clinical improvement and no patient was reported to have complete lesion clearance [23]. In another study among 179 infants with PWS and FSTs I-III, 25.9\% had complete lesion clearance while $41.1 \%$ achieved 76-99\% improvement after 9.8 (mean) treatment sessions using $595 \mathrm{~nm}$ PDL [24]. The results are more superior compared to our data, probably because the population had a lighter skin type, wherein higher fluences can be utilized and also because of the younger age. The degree of lesion improvement can vary per patient and it is important to discuss this prior to treatment to avoid emotional stress due to unrealistic expectations [25].

In 2002, the Thai government started the Universal Health Coverage (UHC) scheme or "30-baht Scheme", which ensures equitable health care access for even the poorest citizens $[26,27]$. An individual included in the UHC has to pay 30 baht (US \$1) per visit for inpatient and outpatient services, accidents, emergencies, and all medications listed in the National List of Essential Medicines (NLEM) [27-30]. Some procedures including cosmetic care, obstetric delivery beyond two pregnancies, organ transplant, chemotherapy, and renal dialysis are not covered by UHC [30]. Unfortunately, laser treatment is classified under cosmetic care even for the treatment of facial PWS. In Siriraj Hospital Bangkok, Thailand, the laser treatment for PWS per session is approximately 200-7500 baht (US \$7-240) depending on the size of the lesion. The results of our study can justify the inclusion of facial PWS laser treatment in UHC. We suggest that the first 10 PDL sessions be included in the coverage, since it is cost-effective in terms of improving the quality of life of the patients by achieving $60 \%$ clinical improvement. The succeeding treatment can be 
given as an option for the patients who wants further management, since the additional clinical improvement was only $5-10 \%$.

One limitation of the study is that the data collected is from a single center, which could also affect the generalizability of the results. Another limitation is the retrospective data collection that can produce incomplete and limited information from the medical charts. Other variables such as dimension of the lesion and complications of the treatment were not included in this study. We recommend that further studies be conducted and may include different government hospitals in Thailand.

\section{CONCLUSION}

Facial PWS has a significant negative effect on the quality of life and psychological health of the patients. In Thailand, the cost of the laser treatment can be a vital factor in influencing the decision of the patient to undergo treatment. In our study, a total of 10 PDL treatment sessions was considered cost-effective as it can achieve $60 \%$ clinical improvement in facial PWS. The number of treatment sessions can be used as a reference to facilitate health coverage not just in Thailand but in other countries with limited resources as well.

\section{ACKNOWLEDGEMENTS}

The authors wish to thank Ms. Phonsuk Yamlexnoi, Ms. Chutikan Kiatphansodsai, and Mr. Poonnapat Kongverawat for their assistance in recruiting the subjects and managing the database.

Funding. No funding or sponsorship was received for this study or in the publication of this article.

Authorship. All named authors met the International Committee of Medical Journal Editors (ICMJE) criteria for the authorship of this article, take responsibility for the integrity of the work as a whole, and have given their approval for this version to be published.
Authorship Contributions. RW and TJ designed the study, analyzed and interpreted the data. YN and NJ acquired the data. TJ performed the statistical analysis. JNCN, CY, TJ and RW drafted the manuscript. WM and TS performed the critical revision of the manuscript.

Disclosures. Rungsima Wanitphakdeedecha, Tatre Jantarakolica, Janice Natasha C. Ng, Chadakan Yan, Yanisorn Nanchaipruek, Nuttagarn Jantanapornchai, Woraphong Manuskiatti and Tatchalerm Sudhipongpracha have nothing to disclose.

Compliance with Ethics Guidelines. Written informed consent was obtained from all subjects prior to their enrollment in the study and the patient's and parents' consent for publication was obtained. This was performed in accordance with the Helsinki Declaration of 1964 and its later amendments, and the ethics approval was granted by the ethics committee of the Siriraj Institutional Review Board. This study has been registered in the Thai Clinical Trials Registry (TCTR) with the identification number TCTR20200909002.

Data Availability. The data generated and analyzed in the current study are available from the corresponding author upon reasonable request.

Open Access. This article is licensed under a Creative Commons Attribution-NonCommercial 4.0 International License, which permits any non-commercial use, sharing, adaptation, distribution and reproduction in any medium or format, as long as you give appropriate credit to the original author(s) and the source, provide a link to the Creative Commons licence, and indicate if changes were made. The images or other third party material in this article are included in the article's Creative Commons licence, unless indicated otherwise in a credit line to the material. If material is not included in the article's Creative Commons licence and your intended use is not permitted by statutory regulation or exceeds the permitted use, you will need to obtain permission directly from the copyright holder. To view a copy of this licence, 
visit http://creativecommons.org/licenses/bync/4.0/.

\section{REFERENCES}

1. Almeida de Arruda JA, Andrade ES, Andrade RA, Pereira JRD, Callou G. Vascular malformation of the face: a rare case with follow-up of 18 years. Acta Stomatol Croat. 2017;51(4):332-335.

2. Ho WS, Chan HH, Ying SY, Chan PC. Laser treatment of congenital facial port-wine stains: longterm efficacy and complication in Chinese patients. Lasers Surg Med. 2002;30(1):44-7.

3. van Raath MI, Bambach CA, Dijksman LM, Wolkerstorfer A, Heger M. Prospective analysis of the port-wine stain patient population in the Netherlands in light of novel treatment modalities. J Cosmet Laser Ther. 2018;20(2):77-84.

4. Ortiz AE, Nelson JS. Port-wine stain laser treatments and novel approaches. Facial Plast Surg. 2012;28(6): 611-20.

5. Shi W, Wang J, Lin Y, et al. Treatment of port wine stains with pulsed dye laser: a retrospective study of 848 cases in Shandong Province, People's Republic of China. Drug Des Dev Ther. 2014;8:2531-8.

6. Yu W, Ma G, Qiu Y, et al. Prospective comparison treatment of 595-nm pulsed-dye lasers for virgin port-wine stain. Br J Dermatol. 2015;172(3):684-91.

7. Li D, Chen B, Zhang H, Yuan Y, Fan W, Ying Z. Retrospective study of the treatment of port-wine stains with 595-nm pulsed dye laser in 261 Chinese patients. Lasers Med Sci. 2020;35(8):1811-9.

8. Liu H, Dang Y, Chai X, Wang Z, Ma L, Ren Q. Treatment of port-wine stains with the 595-nm pulsed dye laser: a pilot study in Chinese patients. Clin Exp Dermatol. 2007;32(6):646-9.

9. Passeron T, Salhi A, Mazer JM, et al. Prognosis and response to laser treatment of early-onset hypertrophic port-wine stains (PWS). J Am Acad Dermatol. $2016 ; 75(1): 64-8$.

10. Hagen SL, Grey KR, Korta DZ, Kelly KM. Quality of life in adults with facial port-wine stains. J Am Acad Dermatol. 2017;76(4):695-702.

11. Troilius A, Wrangsjö B, Ljunggren B. Patients with port-wine stains and their psychosocial reactions after photothermolytic treatment. Dermatol Surg. 2000;26(3):190-6.
12. van Raath MI, Chohan S, Wolkerstorfer A, van der Horst C, Storm G, Heger M. Port wine stain treatment outcomes have not improved over the past three decades. J Eur Acad Dermatol Venereol. 2019;33(7):1369-77.

13. Updyke KM, Khachemoune A. Port-wine stains: a focused review on their management. J Drugs Dermatol. 2017;16(11):1145-51.

14. Faurschou A, Olesen AB, Leonardi-Bee J, Haedersdal M. Lasers or light sources for treating port-wine stains. Cochrane Database Syst Rev. 2011(11): CD007152.

15. Loffeld A, Zaki I, Abdullah A, Lanigan S. Study of patient-reported morbidity following V-beam pulsed-dye laser treatment of port wine stains. Lasers Med Sci. 2005;20(3-4):114-6.

16. Nguyen C, Yohn J, Huff C, Weston W, Morelli J. Facial port wine stains in childhood: prediction of the rate of improvement as a function of the age of the patient, size and location of the port wine stain and the number of treatments with the pulsed dye (585 nm) laser. Br J Dermatol. 1998;138(5):821-5.

17. Schiffner R, Brunnberg S, Hohenleutner U, Stolz W, Landthaler M. Willingness to pay and time tradeoff: useful utility indicators for the assessment of quality of life and patient satisfaction in patients with port wine stains. Br J Dermatol. 2002;146(3): 440-7.

18. Strauss RP, Resnick SD. Pulsed dye laser therapy for port-wine stains in children: psychosocial and ethical issues. J Pediatr. 1993;122(4):505-10.

19. Karsai S, Roos S, Raulin C. Treatment of facial telangiectasia using a dual-wavelength laser system (595 and 1,064 $\mathrm{nm}$ ): a randomized controlled trial with blinded response evaluation. Dermatol Surg. 2008;34(5):702-8.

20. Periyasamy MK, Sekar CS, Rai R. Effectiveness of dual sequential wavelength laser in the treatment of portwine stains-a retrospective study. Indian Dermatol Online J. 2019;10(4):418-21.

21. Tu HD, Li YH, Xie HF, et al. A split-face study of dual-wavelength laser on neck and facial port-wine stains in Chinese patients. J Drugs Dermatol. 2015;14(11):1336-40.

22. Wang T, Chen D, Yang J, Ma G, Yu W, Lin X. Safety and efficacy of dual-wavelength laser $(1064+595 \mathrm{~nm})$ for treatment of non-treated portwine stains. J Eur Acad Dermatol Venereol. 2018;32(2):260-4.

23. Thajudheen CP, Jyothy K, Priyadarshini A. Treatment of port-wine stains with flash lamp pumped 
pulsed dye laser on Indian skin: a six year study. J Cutaneous Aesthet Surg. 2014;7(1):32.

24. Jeon H, Bernstein LJ, Belkin DA, Ghalili S, Geronemus RG. Pulsed dye laser treatment of port-wine stains in infancy without the need for general anesthesia. JAMA Dermatol. 2019;155(4):435-41.

25. Augustin M, Zschocke I, Wiek K, Peschen M, Vanscheidt W. Psychosocial stress of patients with port wine stains and expectations of dye laser treatment. Dermatology. 1998;197(4):353-60.

26. Coronini-Cronberg S, Laohasiriwong W, Gericke CA. Health care utilisation under the 30-Baht Scheme among the urban poor in Mitrapap slum, Khon Kaen, Thailand: a cross-sectional study. Int J Equity Health. 2007;6:11.

27. Limwattananon S, Tangcharoensathien V, Tisayaticom K, Boonyapaisarncharoen T, Prakongsai P.
Why has the Universal Coverage Scheme in Thailand achieved a pro-poor public subsidy for health care? BMC Public Health. 2012;12 Suppl 1(Suppl 1): S6.

28. Towse A, Mills A, Tangcharoensathien V. Learning from Thailand's health reforms. BMJ. 2004;328(7431):103-5.

29. Tangcharoensathien V, Patcharanarumol W, Suwanwela W, et al. Defining the benefit package of Thailand Universal Coverage Scheme: from pragmatism to sophistication. Int $\mathrm{J}$ Health Policy Manag. 2020;9(4):133-7.

30. Damrongplasit K, Melnick GA. Early results from Thailand's 30 Baht Health Reform: something to smile about. Health Aff (Millwood). 2009;28(3): w457-66. 